\title{
E-Service Quality: an investigation of its key dimensions and the discriminatory power in the residential property sector
}

\author{
Justin Beneke: School of Management Studies, University of Cape Town \\ Alexander Acton: School of Management Studies, University of Cape Town \\ Dominic Richardson: School of Management Studies, University of Cape Town \\ Fiona White: School of Management Studies, University of Cape Town
}

\begin{abstract}
Research Statement: With an increase in competition within the South African property sector, real estate agencies need to ensure that their channels are as effective as possible. Using the Internet and mobile technologies represents a new means to reach customers and achieve lower operating costs. This study seeks to ascertain which factors potential buyers consider important when perusing residential property in an online environment. Hence, the dimensions of e-service quality, which constitute their online experience, will be explored. In addition, this research explores buyer typologies and probes whether other forms of technology, such as a mobile interface, may be of commercial value to the realtor.
\end{abstract}

Methodology: The empirical analysis was conducted by means of a quantitative survey. A questionnaire was designed to test the application of the e-service quality construct in the South African real-estate sector. Data was obtained from 300 respondents, across the age spectrum, who filled the criteria of being prospective buyers. Convenience sampling was primarily used to collect responses as the researchers were unable to obtain access to a specific database of listed property buyers.

Results \& Conclusion: As mirrored in other studies of this nature, it was found that trust is paramount when initiating property sales online. All other variables in the construct (site features, information, accessibility, communication, reliability, responsiveness and personalisation) also proved significant. A cluster analysis revealed that older respondents preferred a higher level of support across all attributes of e-service quality - when interacting with online property services. Lastly, the mobile interface appears to appeal to 'students' as well as 'mature workers'. It is surmised that these individuals have access to smart phones capable of being used for accessing property portals. However, the 'young workers' appear less enthusiastic about the mobile interface, seemingly preferring to either access such portals via the Internet or visiting agents personally.

Keywords: real estate, property, e-service quality, Internet, marketing, South Africa.

\section{INTRODUCTION}

With the ever increasing accessibility and proliferation of technology in the mass market, the corporate sector has made strategic advances in adopting the use of these technologies. The Internet, in particular, has become a powerful tool in the arsenal of the corporate marketer (Bond \& Seiler, 2000). South Africa is ranked 52 of 134 for network readiness, with Mauritius being the only sub-Saharan county ranking above South Africa. Although relatively positive, this points to the fact that South Africa is lagging behind the world leaders. Furthermore, South Africa maintains this relatively high ranking because of a predisposition by business to use information and communication technology (ICT). In contrast, individual usage is poor due to low levels of education amongst the population and high access costs (Dutta \& Mia, 2009).

The South African real-estate industry has begun to invest in vast technological infrastructure, including the usage of an online interface. This interface is used not only to market the company and provide vital consumer information, but also to provide a platform for the facilitation of the sale of real-estate (Bidoli \& Tobin, 2006). To this end, the Internet is quickly creating a generation of sophisticated buyers and sellers (Bond \& Seiler, 2000). Whilst it is true to say that e-commerce has been impeded by technological and human barriers, as outlined above, high value industries (e.g. property) are less likely to have suffered the same fate. Buyers now have a wealth of information at their disposal and can quickly and easily check for reputable agents, as well as the profile of various neighborhoods. Sellers can quickly determine which agency is the most prolific and thus list with them. 
The mere presence of online real-estate sites is not sufficient to grow a thriving marketplace. This study considers the application of e-service quality in this high value industry, with a view to informing academics and practitioners of the manner in which consumers assess online property services.

\section{RESEARCH PROBLEM}

This study primarily aims to ascertain the key dimensions of e-service quality, thus highlighting the factors that potential buyers consider important when perusing residential property in an online environment. This will be achieved through a confirmatory factor analysis. As a secondary concern, this research explores the discriminatory power of this construct through an exploratory factor analysis with the aim of discovering potential buyer typologies which could assist in segmenting the online market.

Whilst research in the domain of e-service quality is not in its infancy, the majority of such studies have been conducted on e-commerce oriented corporations (e.g. banking and retail). In contrast, this study relates to a considerably more complex realm which entails lengthy transaction processes, onerous administrative requirements and a high degree of information searches. It is hoped that the study will therefore cover new ground through the exploration of a fundamentally different industry.

\section{LITERATURE REVIEW}

E-service, broadly speaking, may be defined as the role of service in an online environment (Rust \& Lemon, 2001). Following on, the concept of e-service quality may thus be defined as the consumers' overall evaluation and judgment of the delivery of service in a virtual setting (Santos, 2003).

E-service offerings constitute experiences resulting from purchase through, or engagement with, information technology mediated service delivery (Rowley, 2006). The e-service quality construct was derived from what has become a standard construct in scholarly work, namely the SERVQUAL model (Jun, Yang \& Kim, 2003). However, this construct has certainly not been universally accepted as a 'one size fits all' solution and although there are dimensions which frequently occur, researchers have yet to agree on a standard definition which encompasses findings from all studies pertaining to the topic. Compounding this situation is the fact that different authors use different descriptors in labeling these dimensions and thus synergies among the models are difficult to fathom (Rowley, 2006).

Rowley (2006) performed a meta-analysis through collating a number of studies in the area of e-service quality. She found that the following dimensions are the most prominent in terms of measuring this phenomenon: "site features" (25), "security" (24), "responsiveness" (15), "accessibility" (13), "reliability" (13), "information" (10) and "communication" (8). Other themes uncovered include "delivery" (7), "personalisation" (7) and "other" (18). The salient dimensions are discussed below.

\section{Site features}

Site features is in fact not a self-standing dimension of e-service quality, but rather a culmination of multiple, more focused dimensions which authors often refer to collectively. The two most embedded dimensions in this respect are those of website design and ease-of-use.

Website design relates to the structure and aesthetics of an on-line interface, including determinants such as the architecture of the website, the colours, graphics, images, animations and the overall presentation of a website's content and information (Shaohan \& Minjoon, 2003). The web interface is a forum for customers to ascertain valuable information and indicators about the company with which they are dealing. Due to the lack of physical contact inherent in online interactions, customers use visual cues obtained from the website to make inferences as to the credibility and stature of the company. It is thus important that the interface makes a good impression on the prospective or even loyal consumer, so as to gain new business, or merely retain profitable customers of old. 
Research previously conducted showed that a highly important variable in determining whether customers return to a website or not was that of the design features and the emotional experience attached with accessing the site (Jun et al, 2003). It is therefore not difficult to see why companies should place an emphasis on ensuring that the design quality of their online interface is of the highest order (Shaohan \& Minjoon, 2003).

Ease-of-use relates to factors such as the ease with which customers can find web pages from search engine listings, navigate and absorb content from the website, as well as the simplicity with which key variables such as the websites address can be remembered for future use (Jun \& Yang, 2008). The structure of the site and linkages between pages are therefore crucial to ensure that ease-of-use is realised (Jun et al, 2003).

The layout and functionality of features on the website appear pertinent to property buyers. As property is a complex product, information needs to be clearly articulated and presented. In conjunction, tools such as an internal search facility and a bond repayment calculator need to be simple to use.

\section{Information}

Information essentially relates to the quality of text and revolves around providing customer-centric, credible content and services in a timely fashion (Lee \& Lin, 2005; Jun \& Yang, 2008; Janda \& Trocchia, 2003). This is carried out in an effort to reduce the length of an information search, inherently allowing for profitable opportunities (Jun \& Yang, 2008). Companies operating within the online environment must be able to provide customers with concise and easy to understand information, as any poor content could result in a customer leaving the website and thus representing an opportunity spurned (Shaohan \& Minjoon, 2003).

Dated information has proven to be a large detraction for prospective consumers and so the need for relevant information is paramount to online success. Consumers have also been shown to dislike vast quantities of information within the web presence, as it is believed to make the finding of relevant information exceedingly difficult (Jun \& Yang, 2008).

The usefulness and relevancy of applicable information cannot be overstated in the property market. This is crucial in allowing the buyer to evaluate options and ultimately arrive at a purchase decision.

\section{Personalisation}

In an e-service environment there is an intrinsic lack of real-time interaction, and this can discourage online purchasers. Personalisation can overcome this barrier through creating a user-specific interactive environment and even sending communication to users at pre-determined, on-supply or on-demand intervals. The use of 'ruleengines' or 'personalisation software' also increases a site's ability to provide customers with custom information relating to their preferences and interests, as determined by their search behavior (Jun \& Yang, 2008).

Personalisation is, however, no silver bullet. The fact that users are weary of providing personal information to sites has limited the extent to which customization is possible (Lee \& Lin, 2005). Trust, another dimension of e-service quality (discussed below) may, in fact, be able to moderate this risk.

Despite all this, increasingly complex advances in data mining technologies, such as collaborative filtering, now enable websites to analyse real time buying behavior, which allows the site to personally recommend and offer services and products suited to specific users. This technology even permits websites to offer applicable content to infrequent users based on similar user behavior (Shaohan \& Minjoon, 2003). Ultimately, it is critical for businesses to engage customers in personalized dialogue and to learn more about their needs to better anticipate their future preferences (Jun \& Yang, 2008).

Property buyers are often claimed to be "time poor", meaning that they cannot afford to check property sites on a daily basis. Customisation software (e.g. RSS feeds) will allow listings to be pushed to customers when they are 
made available on the site. Hence, the site will intelligently filter content and then dynamically engage with buyers when appropriate. This convenience attribute is likely to find favour with buyers.

\section{Communication}

Communication is defined as keeping customers informed and communicating with them in a language which they understand (Santos, 2003). This relates to the flow of information, both from the company and other users of the site.

Researchers have also embodied, within the communication dimension, the need for variability with regards to languages. Santos (2003) found that more than $90 \%$ of websites operated in cyberspace are composed in English, whereas the mother tongue of $75 \%$ of web customers is not English. The employment of multiple languages should therefore be investigated so as to satisfy the needs of the customer base. Although it is initially time consuming and expensive, effective implementation of such may bring about a larger customer base and thereafter, an elevated level of sales.

A further aspect to the communication dimension is the encouraging of customers to develop and express their views through online communities and forums (Shaohan \& Minjoon, 2003; Lin \& Lee, 2005). It is suggested that through these communities, customers can access valuable guidance from experts or other consumers with similar interests or requirements, as well as alert companies themselves to consumer concerns.

\section{Accessibility}

Whilst communication primarily refers to the content, accessibility refers to the mechanism to retrieve it. Hence, accessibility refers to the ability of companies to offer multiple channels of communication through various touch points and interfaces. This facilitates engagement with the real-estate company through Internet-enabled and mobile-enabled devices (Jun et al, 2003; Jun \& Yang, 2008). The propensity of using a mobile interface and the customers mostly likely to use this channel is explored in the empirical analysis section of this article.

Accessibility also refers to communication platforms such as e-mail, live customer services through online 'chat', push technologies where the flow of information is automatically triggered, as well as conventional channels such as telephone, fax and postal communications (Shaohan \& Minjoon, 2003; Santos, 2003). Researchers have put forward the notion that companies should invest in these capabilities and that companies intercept consumers through monitoring behaviour and proactively offer assistance when need be (Shaohan \& Minjoon, 2003).

\section{Reliability}

Reliability essentially refers to the alignment of expectations and service delivery. According to Jun \& Yang (2008), reliability involves the customer's perceptions of the consistency and security of the service provided by companies operating within an online sphere. This dimension deals primarily with four determinants, namely: a) the correctness of order fulfillment, b) prompt product deliveries, c) accurate billing, and d) timely responses to communiqués between customer and company.

However, the concept of reliability is usually associated with e-commerce companies that dispatch merchandise, as opposed to companies which act more as a shop window than an online store (i.e. which are not used for conducting transactions or sales), (Jun \& Yang, 2008). Nonetheless, the dimension does indeed share some commonality. In essence, reliability still encapsulates maintaining timely communications with customers, ensuring full functionality of the web presence and providing customers with accurate information, as mentioned previously (Lee \& Lin, 2005; Janssen, Semeijn \& Van Riel, 2003). As property buyers are most likely to be discerning consumers, they are less likely to be forgiving with respect to incorrect information on the site, leaks of customer details, etc.

\section{Trust}

Trust has been described as a fundamental ingredient of the relationship between a seller and a buyer (Dimitriadis et al, 2005). Trust is synonymous with credibility and security (Janssen et al, 2003), also highlighted by Rowley 
(2006) as being dominant within e-service quality literature. Credibility essentially relates to the company reputation and confidence consumers embody in the brand, whereas security addresses the technical specifications of the website security, notably privacy policies and payment methods (Jun \& Yang, 2008). The issue of credibility would almost certainly be more pertinent than technical security within the online real estate sector, which is corroborated by other studies (Janssen et al, 2003; Shaohan \& Minjoon, 2003).

The relevance of trust arises due to the lack of personal contact experienced within the online environment. Consumers cannot be sure as to the existence and legitimacy of the company behind an online interface, especially when brand awareness around the company is low (Dimitriadis et al, 2005). Here, brand admiration can play an important role in mitigating issues around credibility and security.

It is suggested that trust in the site is paramount for a real-estate company as it operates in an environment of uncertainty. Purchasing property is far from routinised response behaviour for most individuals, and carries a significant degree of risk for all parties concerned. It is therefore unsurprising that trust in the brand may serve to allay some of these fears.

\section{Responsiveness}

Responsiveness relates to several aspects surrounding the online experience, including the promptness and helpfulness of the service provided by an online operator, as well as the technology on which the interface runs (Lee \& Lin, 2005; Jun \& Yang, 2008). There are thus both human and technological factors at play.

A recent study showed that $42 \%$ of top-ranked websites take longer than five days to respond to e-mail enquiries, did not respond at all, or were merely inaccessible (Jun \& Yang, 2008). However, overly responsive behaviour is also seen to detract from customer satisfaction and thus a degree of moderation is essential (Janssen et al, 2003). Hence, excessive responsiveness can lead to suspicion on behalf of buyers.

The other angle to this dimension involves the style of web site design (e.g. use of high-resolution graphics) as well as the download speeds enabled by the hosting server (Jun \& Yang, 2008). These factors have an influence on the performance of information searches and may also impede navigation capabilities. However, with ever increasing Internet speeds and significant reductions in cost, the connectivity component of responsiveness is gradually improving (Lee \& Lin, 2005).

Responsiveness is likely to be an important consideration for many property buyers. Assuming a level of affluence is required to invest in property, such buyers are likely to be pressed for time and used to a superior level of customer service. A sluggish website, or unreasonable delays in attending to queries, is therefore likely to deter these individuals.

\section{METHODOLOGY}

The sample consisted of South African residents who had purchased, are currently purchasing, or who will in the foreseeable future purchase property. Convenience and snowball non-probability sampling techniques were used in this study in order to identify suitable respondents, and encourage them to participate in the study. Snowballing was useful in the sense that respondents were able to refer the researchers to friends and colleagues at a similar life stage who were also interested in property.

A two tiered approach was adopted. Buyers and prospective buyers were targeted directly, as well as through various real estate companies who administered questionnaires on the researchers' behalf. As no population list was acquired, and a large number of respondents were needed, this sampling approach was advantageous.

Before the administration of the questionnaire, a pre-test was conducted with a selected group of approximately 45 respondents. This was performed in order to ensure that the questionnaire accurately tested the various constructs. 
After the pre-test was conducted, any necessary changes were made, including the addition of a few questions and the re-wording of others. The questionnaire was then distributed.

\section{RESULTS \& DISCUSSION}

Respondents were segmented into two groupings. These subsets included those who had previously used a South African real estate website (152 responses), and those who had not (148 responses). In order to test the e-service construct, only the former cohort was used.

\section{Item-reliability analysis}

In testing the e-service quality construct, the first step taken was to perform an item-reliability analysis, as it gives the researchers a clear indication of the internal reliability of the construct, and helps to ascertain whether the variables are cohesive in their measurement. This is particularly important in the field of exploratory research where models, concepts and constructs are to a large degree, previously untested. As seen in table 1, the Cronbach alpha for the e-service quality construct is 0.85 . This represents a highly correlated construct, implying that all the variables which make up the construct are in fact testing the same phenomenon, namely e-service quality.

\section{Table 1: Item-reliability analysis for the E-Service Quality Construct}

\begin{tabular}{|c|c|c|c|c|c|c|}
\hline \multirow[b]{2}{*}{ Variable } & \multicolumn{6}{|c|}{$\begin{array}{l}\text { Summary for scale: Mean }=16.3289 \text { Std. Dv. }=5.71946 \text { Valid N:152 } \\
\text { Cronbach alpha: } .851515 \text { Standardized alpha: } .856485 \\
\text { Average inter-item corr.: .432219 }\end{array}$} \\
\hline & $\begin{array}{l}\text { Mean if } \\
\text { deleted }\end{array}$ & $\begin{array}{c}\text { Var. if } \\
\text { deleted }\end{array}$ & $\begin{array}{l}\text { StDv. if } \\
\text { deleted }\end{array}$ & $\begin{array}{c}\text { Itm-Totl } \\
\text { Correl. }\end{array}$ & $\begin{array}{l}\text { Alpha if } \\
\text { deleted }\end{array}$ & \multirow{9}{*}{$\begin{array}{l}\text { ESQUAL } 1=\text { Site Features } \\
\text { ESQUAL } 2=\text { Information } \\
\text { ESQUAL } 3=\text { Accessibility } \\
\text { ESQUAL } 4=\text { Communication } \\
\text { ESQUAL } 5=\text { Reliability } \\
\text { ESQUAL } 6=\text { Trust } \\
\text { ESQUAL } 7=\text { Responsiveness } \\
\text { ESQUAL } 8=\text { Personalisation }\end{array}$} \\
\hline ESQUAL1R & 14.59210 & 26.28099 & 5.126499 & 0.544740 & 0.839060 & \\
\hline ESQUAL2R & 14.54605 & 25.61630 & 5.061255 & 0.650617 & 0.827672 & \\
\hline ESC & 14.54605 & 25.918 & 1064 & 0.6 & 261 & \\
\hline ESQUAL4R & 14.17763 & 25.15924 & 5898 & 0.57 & 450 & \\
\hline ESQUAL5R & 14.39474 & 25.22576 & 5.022525 & 0.610188 & 0.831401 & \\
\hline ESQUAL6R & 14.18421 & 24.42659 & 4.942327 & 0.606653 & 0.832208 & \\
\hline ESQUAL7R & 14.36184 & 25.75723 & 5.075158 & 0.630527 & 0.829824 & \\
\hline ESQUAL8R & 13.50000 & 24.88158 & 4.988144 & 0.514687 & 0.845954 & \\
\hline
\end{tabular}

\section{Confirmatory factor analysis}

The researchers made use of a Confirmatory Factor Analysis (CFA) in order to test the validity of the construct and to build evidence for its potential application. In this respect, the manifest variables (items) are tested to see whether they load highly on the relevant latent variable or 'factor'. The relationships being tested are confirmatory in nature, as the statistical analysis is based on preconceived theory. It is preconceived in this case, that the manifest variables (e.g. ESQUAL1R - ESQUAL8R) do in fact load on the factor (e-service quality) and the analysis is merely confirming this assumed relationship.

CFA is a particularly good tool to use in ascertaining whether factors are valid, due to its statistical rigour. A higher score indicates a greater predictive capability of the manifest variable on the latent variable. Thus, when all the scores are acceptable, convergent validity exists. This essentially indicates that all the associated variables converge to one factor. The CFA output for the e-service quality construct is presented in table 2. 
Table 2: Confirmatory analysis for the E-Service Quality Construct

\begin{tabular}{|l|r|r|r|r|}
\hline & \multicolumn{4}{|c|}{ Model Estimates Revised Model } \\
\cline { 2 - 5 } & $\begin{array}{c}\text { Parameter } \\
\text { Estimate }\end{array}$ & $\begin{array}{c}\text { Standard } \\
\text { Error }\end{array}$ & $\begin{array}{c}\mathrm{T} \\
\text { Statistic }\end{array}$ & $\begin{array}{c}\text { Prob. } \\
\text { Level }\end{array}$ \\
\hline (ESQ)-1->[ESQUAL1R] & 0.622 & 0.074 & 8.458 & 0.000 \\
\hline (ESQ)-2->[ESQUAL2R] & 0.676 & 0.068 & 9.896 & 0.000 \\
\hline (ESQ)-3->[ESQUAL3R] & 0.655 & 0.066 & 9.919 & 0.000 \\
\hline (ESQ)-4->[ESQUAL4R] & 0.643 & 0.084 & 7.610 & 0.000 \\
\hline (ESQ)-5->[ESQUAL5R] & 0.686 & 0.078 & 8.789 & 0.000 \\
\hline (ESQ)-6->[ESQUAL6R] & 0.717 & 0.088 & 8.113 & 0.000 \\
\hline (ESQ)-7->[ESQUAL7R] & 0.613 & 0.071 & 8.643 & 0.000 \\
\hline (ESQ)-8->[ESQUAL8R] & 0.643 & 0.097 & 6.612 & 0.000 \\
\hline
\end{tabular}

Key:

ESQUAL 1 = Site Features

ESQUAL 2 = Information

ESQUAL 3 = Accessibility

ESQUAL 4 = Communication

ESQUAL 5 = Reliability

ESQUAL $6=$ Trust

ESQUAL 7 = Responsiveness

ESQUAL 8 = Personalisation

The CFA output shows the predictive capability of the variables on the underlying construct (i.e. e-service quality). In judging the parameter estimates on their strength of association to the construct, the researchers used a similar threshold as is used in exploratory factor analysis (i.e. $\beta>0.7$ ). What can be seen in the above output is that most of the variables do not in fact exceed the cut-off of 0.7 , but are rather between 0.61 and 0.7 . Considering that a figure of 0.7 is not a rigid cut-off as well as the fact that this is indeed exploratory research being conducted in an emerging market, figures such as those achieved for the parameter estimates are, in fact perfectly acceptable.

What the researchers thus uncover in the CFA analysis is that the variable trust $(0.72)$ is in fact the best predictor of the underlying factor, followed by reliability (0.69), information (0.68), accessibility (0.66), communication (0.64), personalisation (0.64), site features (0.62) and responsiveness $(0.61)$. This implies that trust is a better variable to be used when attempting to predict the e-service quality construct than the variable reliability, for example.

\section{Exploratory Factor Analysis}

The researchers opted to run an Exploratory Factor Analysis (EFA) to uncover latent factors underpinning the eservice quality construct. Using Varimax normalized orthogonal rotations during the EFA, it was found that two distinct factors explained $63.79 \%$ of the variation in the data. This is depicted in table 3 .

\section{Table 3: Eigenvalues extracted from the Exploratory Factor Analysis}

\begin{tabular}{|l|r|r|r|r|}
\hline \multirow{2}{*}{ Value } & \multicolumn{4}{|l|}{$\begin{array}{l}\text { Eigenvalues } \\
\text { Extraction: Principal components }\end{array}$} \\
\cline { 2 - 6 } & Eigenvalue & $\begin{array}{c}\text { \% Total } \\
\text { variance }\end{array}$ & $\begin{array}{c}\text { Cumulative } \\
\text { Eigenvalue }\end{array}$ & $\begin{array}{c}\text { Cumulative } \\
\%\end{array}$ \\
\hline 1 & $4.00423 C$ & $50.0528 \varepsilon$ & $4.00423 C$ & $50.0528 \varepsilon$ \\
\hline 2 & 1.09931 C & $13.7413 \varepsilon$ & 5.103541 & 63.79426 \\
\hline
\end{tabular}

As can be seen in table 4, two distinct factors emerged from the exploratory factor analysis, with significant variables (factor loadings of 0.7 and above) occurring in each. Latent factor one consists of the variables: Communication, Trust, Responsiveness and Personalisation. Latent factor two contains the variables: Site Features, Information and Accessibility. Factor loadings show the correlations of each manifest variable with the latent factor. 
Table 4: Factor loadings extracted from the Exploratory Factor Analysis

\begin{tabular}{|c|c|c|c|}
\hline \multirow[b]{2}{*}{ Variable } & \multicolumn{3}{|c|}{$\begin{array}{l}\text { Factor Loadings (V ari max normalized } \\
\text { Extraction: Principal components } \\
\text { (Marked loadings are }>.700000 \text { ) }\end{array}$} \\
\hline & \begin{tabular}{|c|} 
Factor \\
1 \\
\end{tabular} & \begin{tabular}{|c|} 
Factor \\
2 \\
\end{tabular} & Key: \\
\hline ESQUAL1R & $0.09352 \epsilon$ & 0.874634 & \\
\hline ESQUAL2R & $0.32761 \epsilon$ & $0.75413 \mathrm{~A}$ & ESQUAL 1 = Site Features \\
\hline ESQUAL3R & 0.260214 & 0.817404 & \\
\hline ESQUAL4R & $0.76947 £$ & $0.18287 z$ & $\begin{array}{l}\text { ESQUAL } 3 \text { = Accessibility } \\
\text { ESQUAL } 4 \text { = Communication }\end{array}$ \\
\hline ESQUAL5R & $0.47336 €$ & 0.548894 & ESQUAL 5 = Reliability \\
\hline ESQUAL6R & 0.740077 & 0.251404 & ESQUAL $6=$ Trust \\
\hline ESQUAL7R & $0.70268 \subseteq$ & 0.323995 & ESQUAL 7 = Responsiveness \\
\hline ESQUAL8R & $0.73496 \epsilon$ & $0.13105 \mathrm{~A}$ & ESQUAL 8 = Personalisation \\
\hline Expl.Var & $2.58161 \Xi$ & $2.52192 \varepsilon$ & \\
\hline Prp.Totl & $0.32270 \varepsilon$ & 0.315241 & \\
\hline
\end{tabular}

Latent factor one seems to encapsulate a high-technology orientation (which we have labeled 'techno-savvy'), whilst latent factor two seems to encapsulate a more traditional mindset towards e-service quality (which we have labeled 'traditional).

To further analyse the e-service quality variables with regards to consumer preferences, age is added into a nonhierarchical cluster analysis in order to investigate whether age could be used as a significant demographic variable to create typologies. This is depicted in figure 1. 
Figure 1: A plot of means comparing the e-service quality variables and age.

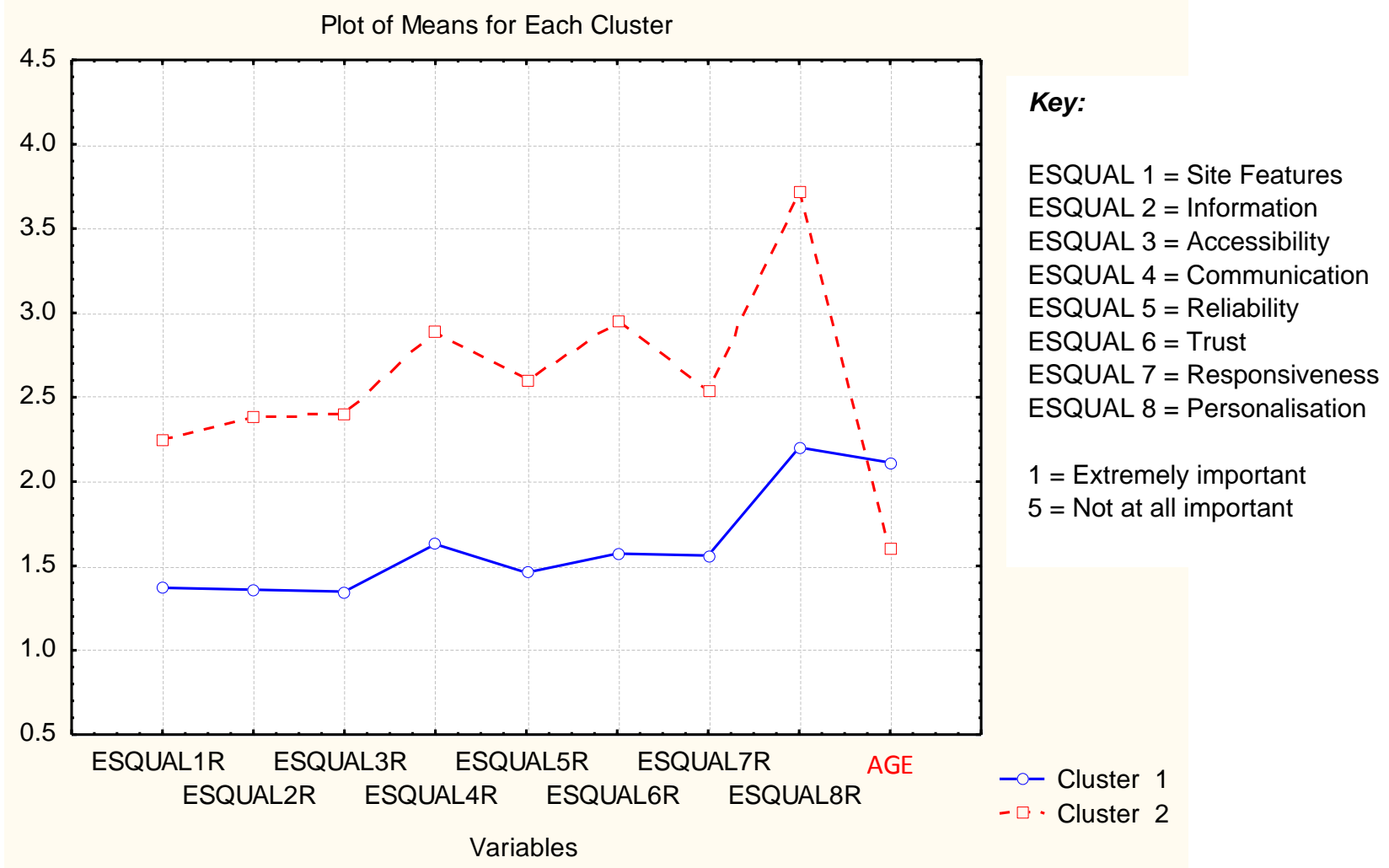

Cluster one shows a slightly older group of respondents that find most of the variables affecting quality to be important to their satisfaction levels, with personalisation being the least important variable. The younger age group, shown in cluster two, found none of the variables as important as cluster one does, some of these to a much larger extent (e.g. personalisation). Their responses to the importance of these variables are seen as either neutral or important, but to a lesser degree relative to those consumers in cluster one. It is thus evident that although the mapping of responses follows a similar pattern for both cohorts, younger respondents consistently placed less emphasis on each attribute.

\section{Probing the second electronic channel}

The need for a mobile presence, along with the diverse functionality that it offers, was also considered in this study. A non-hierarchical cluster analysis was performed (see figure 2) and it was found that three distinct groups exist.

The first group (cluster 3) may be termed 'students'. These individuals are young and have a low income, yet strongly favour the inclusion of a mobile interface, and are thus likely to be techno-savvy. Students also tend to be supported financially and thus have greater access to highly priced advanced mobile phones. The second group (cluster 2) may be called 'young workers'. They are, likewise, relatively young, have slightly higher income than the 'students', yet tend to disagree that the addition of a mobile interface will add value. This may be due to risk aversion in buying high value items with the aid of a mobile interface at this life stage, or may be due to the fact that they are connected to the internet at work and therefore do not see the need for a mobile platform. The third group (cluster 1) may be defined as 'mature workers'. They are in the highest income bracket - mostly earning over R 25 000 as a monthly household income. They are aged between 25 and 44 and, somewhat surprisingly, tend to agree that a mobile interface adds value to property transactions. This group is likely to be somewhat techno-savvy, as these individuals have been in the workplace for some time and may well have gained an appreciation for the impact effective technology can have on productivity. This group also has the financial stability needed to make use 
of highly priced mobile phones. However, their responses were not as enthusiastic as those from the youngest cohort.

Figure 2: A plot of means comparing the variables mobile, age and income.

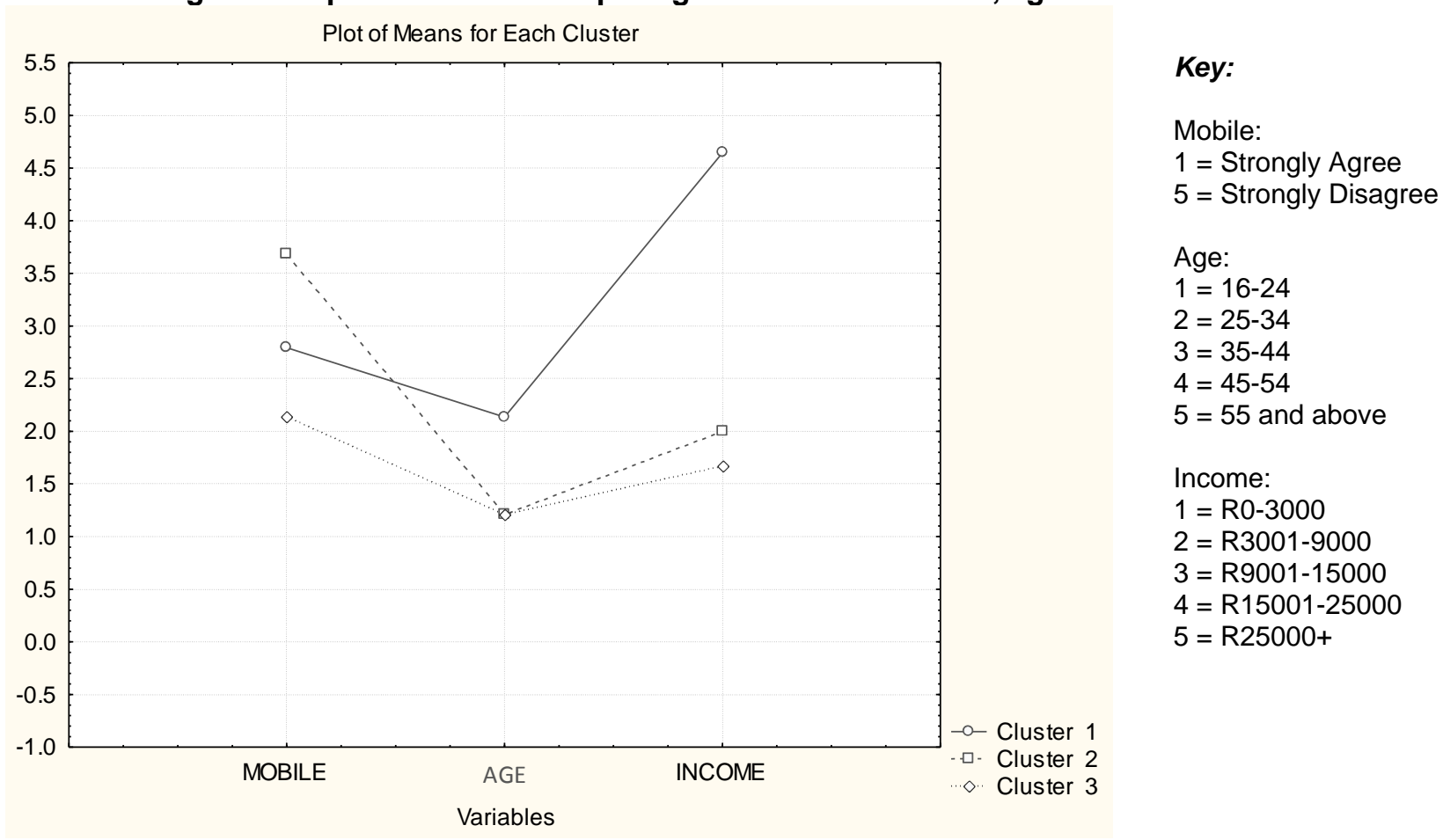

\section{CONCLUSION \& MANAGERIAL IMPLICATIONS}

The study found that trust is paramount when initiating property sales online. This particular variable $(0.72)$ was found to be the leading predictor of the underlying factor, followed by reliability (0.68), information (0.67), accessibility (0.66), communication (0.64), personalisation (0.64), site features $(0.62)$ and responsiveness $(0.61)$.

The results are not unexpected. Trust has been found to be paramount in industries which involve high value transactions and where relationships and reputation are deemed paramount. Reliability is also closely related to trust in that credibility is built through a service that performs consistently well. It may therefore be concluded that real-estate brands, with a strong reputation in the offline world, are likely to be perceived as superior in terms of their online presence. Therefore, the halo effect of such brands is likely to be carried forward into the online realm. Our research also serves to confirm prior studies which have also pointed to a role played by other variables, most notably site features, information and accessibility. These technical facets add value to the service and are, likewise, crucial to ensuring the customer has a pleasant experience whilst considering property online. As such purchases are high risk in nature, each facet has a role to play in lowering the level of perceived risk.

A cluster analysis revealed distinctive differences between the perceptions of younger and older consumers towards buying property online. The former group appears to find none of the above mentioned variables as important as the latter group does. However, on the whole, the patterns for both groups exhibited a similar profile in terms of relative importance. 
Considering the variable age, it must be stated that although younger and more techno-savvy consumers will be the prime market for the real estate industry in years to come, the industry cannot afford to neglect those consumers who are currently most active within the market. These consumers are generally of an older nature due to their accrued wealth and as such, have a more traditional mindset with respect to service and support required. To successfully reach, and avoid jeopardising the relationships with these consumers, the human factor, including the aid of offline facilities, remains important.

The mobile interface appears to appeal to 'students' as well as 'mature workers'. It is surmised that these individuals have access to smart phones capable of being used for accessing mobile property portals. However, it was found that 'young workers' appear less enthusiastic about the mobile interface, seemingly preferring to either access such portals via the Internet, or through visiting agents personally. This may be attributed to a number of reasons. As first-time buyers, 'young workers' may be somewhat risk averse to using new technology for a high involvement purchase. It should also be noted that smart phones are a relatively new phenomenon and as such, 'students' (the youngest cohort) may be more progressive with respect to adopting this technology and being open to partake in mobile commerce activities. It should also be noted that students are more likely to be aspirational buyers of property than serious buyers of property at this life stage. This may also influence their viewpoint - their outlook on property marketing channels may be quite different at the actual time of purchase.

Finally, it should be acknowledged that this is a cross-sectional study which serves to reflect a scenario at a particular point in time. Further studies in due course are therefore recommended to glean insights into the amalgamation of technology and residential property marketing, as well as the impact that e-service quality has on decision making in this context. As mobile technology matures and consumers become comfortable with electronic channels, confidence in buying higher value items through this medium will surely increase, and present exciting opportunities to marketers in this field.

\section{LIST OF REFERENCES}

Bidoli, M \& Tobin, PKJ. 2006, "Factors affecting the adoption of Voice over Internet Protocol (VolP) and other converged IP services in South Africa", South African Journal of Business Management, Vol. 37, No. 1, pp. 3140.

Bond M.T. \& Seiler M.J., 2000. "Uses of Websites for Effective Real Estate Marketing." Journal of Real Estate Portfolio Management, Vol. 6, No. 2, pp. 203.

Chang H.J. Villegas J. 2008. "Mobile Phone Users' Behaviors: the Motivation Factors of the Mobile Phone User", International Journal of Mobile Marketing, Vol. 3, No. 2, pp. 4-14.

Dimitriadis, S., Gounaris, S. \& Stathakopoulos, V. 2005, "Antecedents of perceived quality in the context of Internet retail stores", Journal of Marketing Management, Vol. 21, pp. 669-700.

Dutta, S. \& Mia, I. 2009, "The Global Information Technology Report 2008-2009, Mobility in a Networked World.", URL: http://www.mcit.gov.eg/General/Global\%20IT\%20Report\%202008-092009331155142.pdf [Accessed 04 May 2009].

Hise, R. T. 2000, “E-Satisfaction: An initial examination”, Journal of Retailing, Vol. 76, No. 3, pp. 309-322.

Janda, S. \& Trocchia, P.J. 2003, "How do consumers evaluate Internet retail service quality?", Journal of Services Marketing, Vol. 17, No. 3, pp. $243-253$.

Janssen, W., Semeijn, J. \& Van Riel, A.C.R. 2003, "E-service quality expectations: A Case study" Journal of Total Quality Management, Vol. 14, No. 4, pp. 437-450. 
Jeong, A., Hong-bumm, K. \& Woo Gon, K. 2003. "The effect of consumer-based brand equity on firms' financial performance.", Journal of Consumer Marketing, Vol. 20, No. 4, pp 335 - 351.

Jun, M., Yang, Z. \& Kim, D. 2003. "Customers' perceptions of online retailing service quality and their satisfaction.", Journal of Quality and Reliability Management, Vol. 21, No. 8, pp. 817-840.

Jun, M. \& Yang, Z. 2008. "Consumer perception of e-service quality: From Internet purchaser and non-purchaser perspectives", Journal of Business Strategies, Vol. 25, No. 2, pp. 59-84

Lee, G.G. \& Lin, H.F. 2005, "Customers perceptions of e-service quality in online shopping", International Journal of Retail and Distribution Management, Vol. 3, No. 2, pp. 161-176.

Luo, Y \& Tung, R. L. 2007, "International Expansion of Emerging Market Enterprises: A Springboard Perspective.", Journal of International Business Studies, Vol. 38, pp. 481-498.

McKinney V., Yoon K. \& Zahedi F. 2002, "The Measurement of Web-Customer satisfaction: An Expectation and Disconfirmation Approach.”, Information Systems Research, Vol. 13, No. 3, pp. 296-315.

Merrilees, B. \& Wong, H, Y. 2008, "The performance benefits of being brand-orientated.", Journal of Product and Brand Management, Vol. 17, No. 6, Pp. 372-383.

Rowley, J. 2006, "An analysis of the e-service literature: towards a research agenda.", Journal of Internet Research, Vol. 16, No. 3, pp. $339-359$

Santos, J. 2003, "E-service quality: a model of virtual service quality dimensions", Managing Service Quality, Vol. 13 , No.3, pp. $233-246$.

Shankar V., Smith A.K. \& Rangaswamy A. 2003, "Customer satisfaction and loyalty in online and offline environments." International Journal of Research in Marketing, Vol. 20, No. 2, pp.153-175.

Shaohan, C. \& Minjoon, J. 2003, “Internet users' perceptions of online service quality: a comparison of online buyers and information searchers", Managing Service Quality, Vol. 13, No. 6, pp. 504.

Szymanski, D. M., David H. H. 2001, "Customer satisfaction: A meta-analysis of the empirical evidence.", Journal of Acad. Marketing Sci, Vol. 29, No.1, pp. 16-35. 


\section{APPENDIX: SYNOPSIS OF SCALES INCLUDED IN QUESTIONNAIRE}

The following table includes a list of the e-service quality dimensions considered, including descriptions.

\begin{tabular}{|l|l|}
\hline Dimension & Description \\
\hline Site Features & Website design, functionality and ease of use \\
\hline Information & Quality and scope of the content \\
\hline Accessibility & $\begin{array}{l}\text { Channels and facilities through which information } \\
\text { may be accessed }\end{array}$ \\
\hline Communication & $\begin{array}{l}\text { Language and community-oriented interaction } \\
\text { Reliability }\end{array}$ \\
\hline Trust & $\begin{array}{l}\text { Credibility of the company and the technical } \\
\text { security of the website }\end{array}$ \\
\hline Responsiveness & $\begin{array}{l}\text { Timeliness of the website and company } \\
\text { employees in delivering customer support. }\end{array}$ \\
\hline Personalisation & $\begin{array}{l}\text { Customisation of the user experience through } \\
\text { information presentation and flow. }\end{array}$ \\
\hline
\end{tabular}

